\title{
JOURNAL
}

of Health Inequalities

\section{Declaration from the World Conference on Family Health, Calisia, 2019}

\author{
Leif Edvard Aarø ${ }^{1}$, Witold A. Zatoński ${ }^{2,3}$, Mateusz Zatoński ${ }^{2,4}$, Andrzej Wojtyła ${ }^{5}$ and advisory group \\ 'Division of Mental and Physical Health, Norwegian Institute of Public Health, Bergen, Norway \\ ${ }^{2}$ Health Promotion Foundation, Nadarzyn, Poland \\ ${ }^{3}$ European Observatory of Health Inequalities, the President Stanisław Wojciechowski State University of Applied Sciences \\ in Kalisz, Poland \\ ${ }^{4}$ Tobacco Control Research Group, Department for Health, University of Bath, United Kingdom \\ ${ }^{5}$ The President Stanisław Wojciechowski State University of Applied Sciences in Kalisz, Poland
}

* Declaration advisory group:

Sonia Angell (Assistant Clinical Professor of Medicine, Columbia University College of Physicians and Surgeons; former Director NYC Health Department, New York, USA), Peter Boyle (International Prevention Research Institute, Lyon, France), Rob Branston (Associate Professor, Institute for Policy Research, University of Bath, United Kingdom), Allan Brandt (Professor of the History of Science, Harvard University, USA), Cliff Douglas (Vice President for Tobacco Control, American Cancer Society, Atlanta, USA), Zbigniew Gaciong (Director of the Clinic of Internal Medicine, Hypertension, and Angiology, Medical University of Warsaw, Poland), Aleksandra Herbeć (UCL Centre for Behaviour Change, University College London, United Kingdom), Carlo LaVecchia (Professor at the Department of Clinical Sciences and Community Health, University of Milan "La Statale", Italy), Kinga Janik-Koncewicz (Project Director at the Health Promotion Foundation, Nadarzyn, Poland), Krystian Kinastowski (the Mayor of the City of Kalisz, Poland), Michał Kleiber (Polish Academy of Sciences), Knut-Inge Klepp (Professor, Director, Division of Mental and Physical Health, Norwegian Institute of Public Health, Oslo, Norway), Maurice B. Mittelmark (Professor Emeritus, Department of Health Promotion, University of Bergen, Norway), Jacek Moskalewicz (Head of the Department of Studies on Alcoholism and Drug Dependence at the Institute of Psychiatry and Neurology, Warsaw, Poland), John O’Dowd (Honorary Clinical Senior Lecturer, Institute of Health \& Wellbeing, University of Glasgow, United Kingdom), Lilia Olefir (Executive Director, "Life" Advocacy Center, Kyiv, Ukraine), Grzegorz Opolski (Head of the First Department of Cardiology, Medical University of Warsaw, Poland), Jonathan Samet (Colorado School of Public Health, Aurora, Colorado, USA), Małgorzata Stelmach (Foundation of Women's Health, Warsaw, Poland), Marcin Wojnar (Professor of Psychiatry, Chair of the Department of Psychiatry, Medical University of Warsaw, Poland)

\begin{abstract}
On June 9-10, 2019 researchers and public health experts from several countries participated in the International Conference on Family Health in Kalisz (Calisia), Poland. An important focus of the discussion was health inequalities in Europe, regional as well as within countries, particularly inequalities related to non-communicable diseases. The present document constitutes the participants' call for action to reduce health inequalities in Europe.
\end{abstract}

KEY WORDS: Europe, health, inequalities, public health, health promotion, governance.

ADDRESS FOR CORRESPONDENCE: Leif Edvard Aarø, Ph.D., Division of Mental and Physical Health, Norwegian Institute of Public Health, P.O. Box 973, Sentrum, NO-5808 Bergen, Norway, e-mail: leea@fhi.no

\section{THE CHALLENGE}

The health situation in the Central and Eastern European (CEE) countries has improved significantly during the last three decades. However, the health gap between the CEE countries and Western
Europe remains an unresolved challenge. The Closing the health gap in European Union report, published in 2008, was the first comprehensive attempt to document, and begin addressing, these regional differences [1]. 
Considerable health inequalities persist across different regions of Europe. Western European countries ${ }^{1}$ continue to enjoy the highest life expectancy levels, followed by Central Europe ${ }^{2}$, with Eastern Europe ${ }^{3}$ having the lowest level of life expectancy. Differences between Western Europe and the two other regions are even more pronounced when, in addition to premature mortality, years lost due to disability are also taken into account. These regional inequalities are largely caused by differences in risk factors related to non-communicable diseases (NCDs). This includes behavioural risk factors such as cigarette smoking, unhealthy diet, alcohol and substance use, physical inactivity, and differences in biological risk factors like high body mass index, high blood pressure and high LDL cholesterol. High levels of inequality exist also within countries in Europe. Better health and lower levels of risk are associated with higher levels of education and higher income [2]. Inequalities within countries are also challenging with regard to gender, ethnicity, and disability ${ }^{4}$.

The persisting health gaps within and across countries in Europe constitute an important factor in reducing human capital and compromising economic and social progress in countries in Central and Eastern Europe.

Target number 4 within Goal 3 of the Sustainable Development Goals (SDGs) of the United Nations is to reduce premature mortality from NCDs by a third by 2030 [3]. In order to achieve reduction in socioeconomic inequalities caused by NCDs, population subgroups, individual countries, and regions of Europe with high levels of NCDs must reduce premature mortality caused by NCDs at an even higher pace [4]. Action to reduce inequalities in NCDs within countries as well as across countries and regions of Europe is urgently needed.

\section{CHALLENGES IN POLAND}

Experiences of Poland may serve as an illustration of the kind of public health challenges confronting countries in Central and Eastern Europe.

- The risk of death before 65 years of age in Poland is much higher than in Western Europe.

- Tobacco use is the leading cause of premature mortality in Poland (see Appendix 1). Smoking rates have been halved since the 1990s, but 8 million Poles are still smokers, and smoking causes 40,000 premature deaths every year [5].

- During the last decade, alcohol-related diseases have turned out to be a rapidly growing challenge in Poland [6].
- Decline in CVD morbidity and mortality in young and middle aged adults has slowed down during the last decades.

- Life expectancy in both sexes in Poland has stagnated since 2014.

Countries vary widely in their ability to take action against NCDs. Progress has been limited, even though many recommendations exist.

The WHO High Level Commission on NCDs, 2018

\section{GOVERNANCE}

The Action Plan for the Prevention and Control of Non-communicable Diseases in the European Region of the WHO provides a comprehensive framework for policies and action [7]. In addition to reducing the burden of disease and improving quality of life, making healthy life expectancy more equitable is a key goal of this action plan.

In order for any country to improve population health effectively, including action to reduce inequalities and inequities in health, strong governance is fundamental. Strengthening of public health governance is particularly urgent in Central and Eastern Europe. Important elements of adequate public health governance include strong political commitment, strong coordination at all levels and across sectors, surveillance, research and evaluation, and public health education and training for relevant professions and stakeholders.

Traditionally, public health has focussed on influencing individual behavioural choices through health education. This has contributed to increased socioeconomic inequality and inequity. A more balanced orchestration of approaches, emphasizing structural and contextual determinants, is needed in order to promote health for all. Structural approaches, such as those prescribed by the WHO Framework Convention on Tobacco Control, include restrictions on marketing, use of taxation, use of counter-marketing, restrictions on smoking in public places, and other policy measures - all of which have proved their strong and positive impact in the field of tobacco control globally [8]. These experiences should be used as models in planning legislative and fiscal policies aimed to create environments conducive to healthy lifestyles.

\section{COMMUNITIES AND FAMILIES}

Socioeconomic inequalities in behavioural determinants of health have been formed during "diffusion"

\footnotetext{
Western Europe: Andorra, Austria, Belgium, Cyprus, Denmark, Finland, France, Germany, Greece, Iceland, Ireland, Israel, Italy, Luxembourg, Malta, Netherlands, Norway, Portugal, Spain, Sweden, United Kingdom.

${ }^{2}$ Central Europe: Albania, Bosnia and Herzegovina, Bulgaria, Croatia, Czech Republic, Hungary, Macedonia, Montenegro, Poland, Romania, Serbia Slovakia, Slovenia.

${ }^{3}$ Eastern Europe: Belarus, Estonia, Latvia, Lithuania, Moldova, Russian Federation, Ukraine.

${ }^{4}$ The International Classification of Functioning, Disability and Health (ICF) defines disability as an umbrella term for impairments, activity limitations and participation restrictions; see: https://www.who.int/news-room/fact-sheets/detail/disability-and-health.
} 
processes. Well-educated and high-income groups have changed their behaviours first, and less privileged groups have to some extent followed. Even when these processes of change unfold over longer periods, there may still be large groups who do not experience improved health, and who will only benefit from targeted approaches such as combinations of community-based health impact assessment and community development programmes [9]. Of fundamental importance are also policies of proportionate universalism [10] where resources are deployed incrementally for groups, depending on their levels of need.

Stable and supportive communities promote thriving, wellbeing and positive mental health. Families may foster health literacy and healthy lifestyles amongst children and adolescents. Families and communities represent important settings for health promoting interventions. Working directly with families can help prevent the transmission of poor health from one generation to the next.

Community-and-family-centred public health approaches are important in reducing inequalities in health. Further development and research is important to improve policies and interventions for underserved groups [11].

In the context of Health Promotion [12] and New Public Health, comprehensive, empowering and effective strategies for public health action have been developed. By strengthening public health governance and by applying such strategies, every country should be able to improve the health of their populations and reduce health inequalities.

\section{CONCLUSIONS}

Consistent with the WHO Action Plan for the Prevention and Control of Non-communicable diseases in the WHO European Region, the Montevideo Roadmap 2018-2030 on NCDs, and recommendations from the WHO Independent High-Level Commission on NCDs, participants at the Calisia conference [13] call on international organizations, governments, NGOs and all stakeholders to promote strong governance for public health and comprehensive action across sectors in all countries in order to prevent disease, promote health, and reduce inequalities.

Health must be for all, irrespective of location, gender, age, position, and circumstances.

\section{DISCLOSURE}

The authors report no conflict of interest.

\section{References}

1. Zatoński W and the HEM Project team. Closing the health gap in European Union. Cancer Center and Institute, Warsaw 2008.

2. World Health Organization. Review of social determinants and the health divide in the WHO European Region: final report. World Health Organization, Regional Office for Europe,
Copenhagen 2013. Available from: http://www.euro.who. int/_data/assets/pdf_file/0004/251878/Review-of-social-determinants-and-the-health-divide-in-the-WHO-EuropeanRegion-FINAL-REPORT.pdf (accessed: 20 May 2019).

3. World Health Organization. Sustainable development goal 3: Health. Available from: https://www.who.int/topics/sustainable-development-goals/targets/en/ (accessed: 1 June 2019).

4. Nishtar S, Niinistö S, Sirisena M, et al. Commissioners of the WHO Independent High-Level Commission on NCDs. Time to deliver: report of the WHO Independent High-Level Commission on NCDs. Lancet 2018; 392 (10143): 245-252.

5. Jassem J, Przewoźniak K, Zatoński W. Tobacco control in Poland-successes and challenges. Transl Lung Cancer Res 2014; 3 (5): 280-285

6. Zatoński WA, Sulkowska U, Zatoński MZ, et al. Alcohol taxation and premature mortality in Europe. Lancet 2015; 385 (9974): 1181.

7. World Health Organization. Action plan for the prevention and control of noncommunicable diseases in the WHO European Region. World Health Organization, Regional Office for Europe, Copenhagen 2016. Available from: http://www.euro. who.int/en/health-topics/noncommunicable-diseases/pages/ policy/publications/action-plan-for-the-prevention-and-control-of-noncommunicable-diseases-in-the-who-european-region-20162025 (accessed: 20 May 2019).

8. World Health Organization. WHO Framework Convention on Tobacco Control. Available from: https://www.who.int/fctc/ cop/about/en/ (accessed: 20 May 2019).

9. Mittelmark MB, Gillis DE, Hsu-Hage B. Community development: The role of health impact assessment. In: Health Impact Assessment: Concepts, Methods and Applications. Kemm J, Parry J, Palmer S (eds.). Oxford University Press, London 2004; 143-152.

10. Marmot M, Goldblatt P, Allen J, et al. Fair society, healthy lives. The Marmot review. Institute of Health Equity, Department for Epidemiology \& Public Health, University College London, London 2010. Available from: http://www.instituteofhealthequity.org/resources-reports/fair-society-healthy-livesthe-marmot-review/fair-society-healthy-lives-full-report-pdf. pdf (accessed: 20 May 2019).

11. National Cancer Institute. Division of Cancer Control and Population Sciences. Monograph 22: A Socioecological Approach to Addressing Tobacco-Related Health Disparities. Available from: https://cancercontrol.cancer.gov/brp/tcrb/monographs/22/ (accessed: 20 May 2019).

12. World Health Organization. The Ottawa Charter for Health Promotion. Available from: https://www.who.int/healthpromotion/conferences/previous/ottawa/en/ (accessed: 20 May 2019).

13. Janik-Koncewicz K. Report from the Calisia World Conference on Family Health, Kalisz, Poland, 9-10 June 2019. J Health Inequal 2019; 5 (1): 2-10.

\section{AUTHORS' CONTRIBUTIONS}

LEA has led the conceptualising and writing of the declaration, and has coordinated the other authors and advisory group members. 


\section{Call for the reintroduction of the National Programme for Limiting the Health Consequences of Tobacco Smoking}

All authors have contributed to the text of the declaration. The advisory group members have provided strategic feedback on the content of the declaration.

Smoking cigarettes continues to be the most important factor threatening the health and leading to premature mortality of Poles - this applies to cancers, particularly lung cancer, vascular diseases, cardiac diseases, chronic obstructive pulmonary disease, and many other disorders.

There are still 8 million smokers in Poland, who "burn through" billions of Polish zloty, consuming over 40 billion cigarettes every year. The estimated health toll of smoking in Poland is 40,000 premature deaths a year, including almost 23,000 deaths due to lung cancer. As many as 25,000 infants are exposed to tobacco smoke already in their mothers' wombs. This health catastrophe is fully preventable, as evidence by the example of countries such as Canada, Australia, or the Scandinavian countries.

We appeal to Polish politicians to reintroduce the National Programme for Limiting the Health Consequences of Tobacco Smoking, aborted in 2015 for unexplainable reasons. A return to quick declines in smoking prevalence is the only way to resume the increase in life expectancy in Poland, which has been stalling in the last five years.

Representatives of:

the Health Promotion Foundation, MSD Foundation for Women's Health, Polish Group of Lung Cancer, Lung Cancer Forum
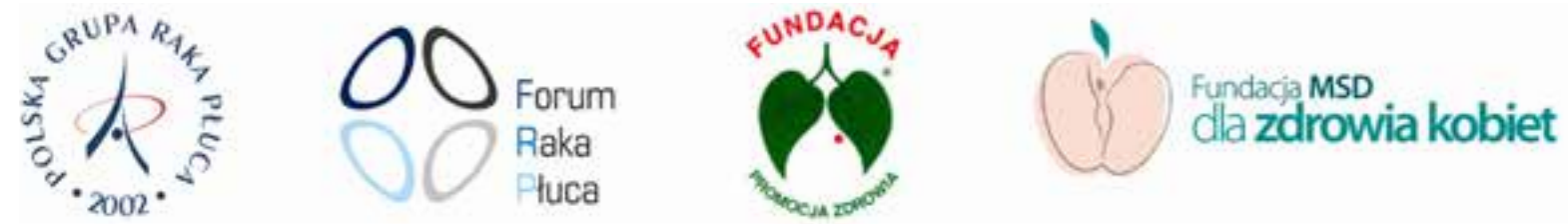